\title{
A REVIEW OF CONTEMPORARY TECHNIQUES FOR MEASURING ERGONOMIC WEAR COMFORT OF PROTECTIVE AND SPORT CLOTHING
}

\author{
Yetanawork Teyeme*1, ${ }^{\star}$ Benny Malengier ${ }^{1}$, Tamrat Tesfaye $^{2}$, Izabela Ciesielska-Wrobel'1, \\ Atiyyah Binti Haji Musa', and Lieva Van Langenhove ${ }^{1}$ \\ 1 Ghent University, Faculty of Engineering and Architecture, Department of Materials, Textiles and Chemical Engineering, Technologiepark 907,9052 \\ Zwijnaarde, Belgium \\ 2 Bahir Dar University, Ethiopian Institute of Textile and Fashion Technology, Bahir Dar, Ethiopia \\ Corresponding author. E-mail: yetanaworkwubneh.teyeme@UGent.be
}

\begin{abstract}
:
Protective and sport clothing is governed by protection requirements, performance, and comfort of the user. The comfort and impact performance of protective and sport clothing are typically subjectively measured, and this is a multifactorial and dynamic process. The aim of this review paper is to review the contemporary methodologies and approaches for measuring ergonomic wear comfort, including objective and subjective techniques. Special emphasis is given to the discussion of different methods, such as objective techniques, subjective techniques, and a combination of techniques, as well as a new biomechanical approach called modeling of skin. Literature indicates that there are four main techniques to measure wear comfort: subjective evaluation, objective measurements, a combination of subjective and objective techniques, and computer modeling of human-textile interaction. In objective measurement methods, the repeatability of results is excellent, and quantified results are obtained, but in some cases, such quantified results are quite different from the real perception of human comfort. Studies indicate that subjective analysis of comfort is less reliable than objective analysis because human subjects vary among themselves. Therefore, it can be concluded that a combination of objective and subjective measuring techniques could be the valid approach to model the comfort of textile materials.
\end{abstract}

\section{Keywords:}

Ergonomic wear comfort, protective clothing, sportswear, human body movements, evaluation methods

\section{Introduction}

Ensuring human comfort $(\mathrm{HC})$ is a very complex task as it depends on the influences of a human's psychological and physiological states and the surrounding environmental conditions. $\mathrm{HC}$ also greatly depends on the clothing, interfering with human psychology and physiology, and preventing the harmful influences of external conditions [1, 2]. The more complex the clothing, the more difficult it is to establish its impact on $\mathrm{HC}$. The complexity of human-clothing interactions arises due to the interactions between the body and the clothing, as well as by the ability of the garment to protect and reassure comfort to the user. Clothing as a near environment of the human body plays a vital role in achieving $\mathrm{HC}$.

Over the past few decades, extensive and systematic investigations of clothing comfort, clothing functionalities and abilities that affect $\mathrm{HC}$, and the ergonomic wear comfort have been conducted, specifically in the context of all sorts of protective clothing (PC) [3-5]. In this context, the greatest number of studies has been performed in relation to the thermophysiological wear comfort [6,7], while the role of other types of $\mathrm{HC}$, e.g., sensorial wear comfort [8, 9], ergonomic wear comfort (also known as wear comfort) $[10,11]$ and the psychological wear comfort, has been less investigated. There are several possible reasons for this: (a) other types of $\mathrm{HC}$ are not considered crucial for human existence; (b) they are difficult to test, measure and analyze; (c) a large amount of data supporting the findings would have used novel methodologies, thus would require requiring the engagement of human subjects; (d) so far, there has been an instrumental and methodological shortage in the context of analyzing these remaining types of $\mathrm{HC}$ in a reliable manner [12]. In order to support studies on $\mathrm{HC}$, especially on ergonomic wear comfort, we need a thorough review of well-designed methodologies and instrumentations to study ergonomic wear comfort in the context of protective and athletic outfits. The mechanisms and fundamental principles associated with human physiological needs, comfort attributes of clothing, and their interaction with a variety of environments have been formalized and established.

In this context, the development of clothing should consider the anatomical features of individuals (anthropometric data), biomechanical features, functional needs (skills and physical limitations while performing occupational or sport activities), fabric suitability and its structure. These factors can overlap and correlate significantly with the subjective evaluation performed and provided by the users, especially with regard to usability, wearability, and safety. Functional clothing, by definition, is user-requirement specific and designed or engineered to meet the performance requirements of the user under sometimes-extreme conditions. Therefore, unlike everyday 
clothing, the process of designing functional clothing begins and ends with the user-specific requirements based on the outcomes of objective assessments [13]. These requirements, whether for performance or for comfort, are determined by the environment in which the user operates, and the activities that he or she performs. Clothing designed specifically for certain functionalities has been shown to cause heat stress, as well as reduce task efficiency and the range of motion of the wearer [14]. The process of design, therefore, begins by first establishing the many requirements of the user. Nevertheless, ergonomic design processes, such as materials selection, size and fit, pattern making, assembling and finishing, have also been listed out.

In recent times, the consumer's interest towards $\mathrm{HC}$ of the textile wear is increasing. Apart from the three major types of comfort mentioned, there are several different aspects closely related to these types of comfort, e.g., the effect of the environment, fabric hand, moisture management within the fabric and the clothing setup [13, 14], thermal management and psychological comfort versus psychological wear comfort, all dependent on time and geographical region [15]. Thermal and tactile comfort is most often discussed [16]. Additionally, the interactions of clothing with the human skin and various factors that affect the fitting of the garment to the human body have been discussed by many researchers [17]. Furthermore, the human anatomy and body movement should be taken into account [18]. This helps to simplify the adaption of the clothing to the human body so that comfort is confirmed.
On the basis of literature review, the classification of ergonomic wear comfort assessment techniques for PC and sports clothing is presented in Figure 1. The aim of this review is to provide a perspective on the primary functionality requirements of the ergonomic comfort aspects related to the interaction of garments with the human body, injury prevention and performance enhancement in the context of PC and sports clothing. In particular, in order to understand the ergonomic aspects of clothing comfort, evaluating human attributes and abilities in certain activities, reducing discomfort level, and ensuring safety are crucially important to accomplish "ideal" comfort while maintaining the effectiveness and enhancing the level of performance $[19,20]$. We focus in this paper mainly on the issues related to the ergonomic wear comfort aspects of sportswear and $\mathrm{PC}$ with specific reference to the requirements. Within this broader context, particular emphasis is given to freedom of movement (besides the primary requirements for sportswear and PC) and product usability testing.

\section{Clothing ergonomics}

Ergonomics integrates with multiple disciplines, including biological anthropology, genetics, anatomy, physiology, biomechanics, psychology, and design, to improve objects and processes for human use [21, 22]. According to Reilly [23], no one can achieve "world-class" performance in a poor ergonomic environment. Thus, ergonomics design can significantly contribute to, e.g., the design of sports equipment, workplace interventions, and training regimes. Such design should not

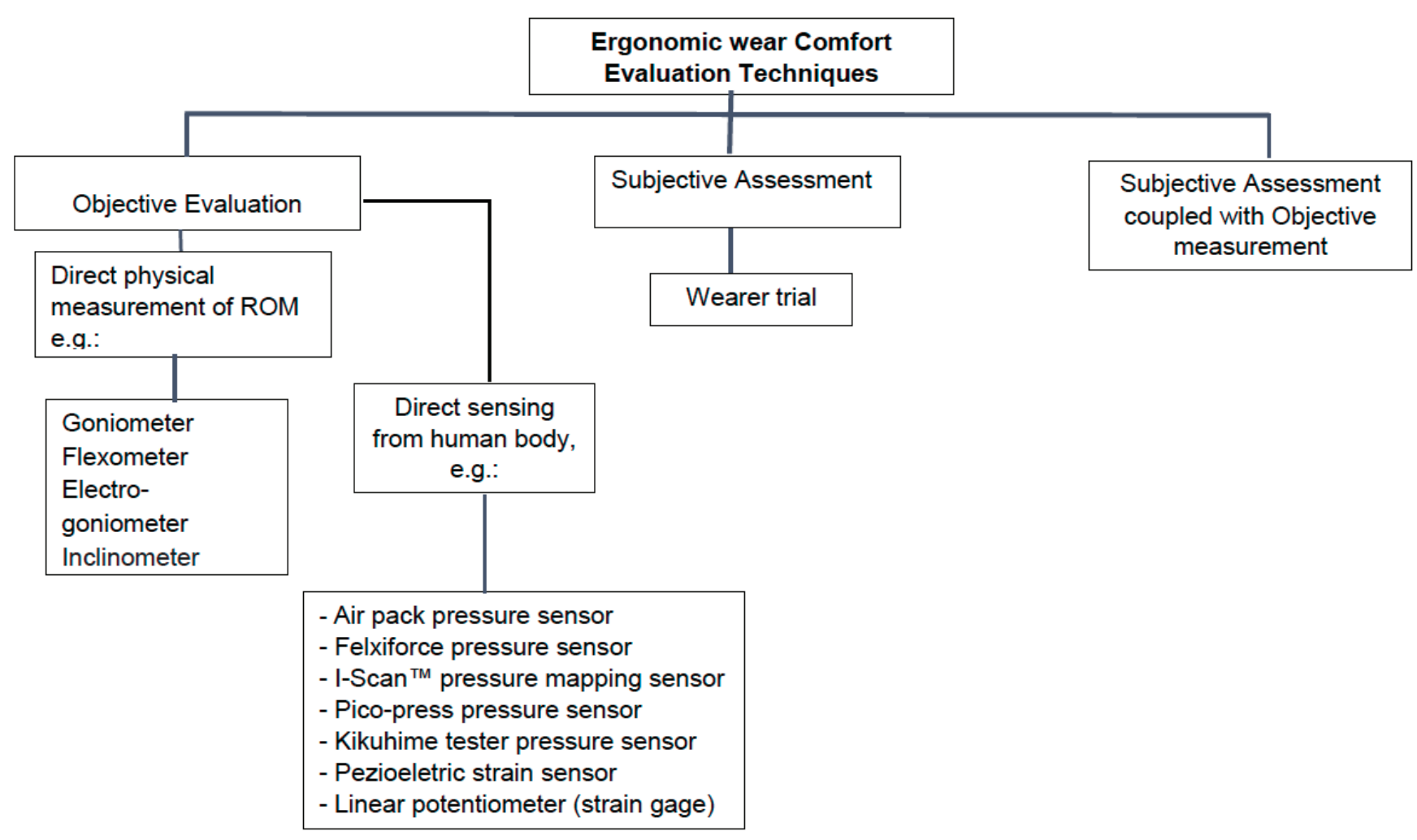

Figure 1. Contemporary evaluation framework for ergonomic wear comfort. 
only promote and support a high level of performance but also prevent the occurrence of injuries.

"Clothing ergonomics is a sub-discipline concerned with the study of the relationship between humans and their clothing, focusing on the body's shape and other characteristics of the starting motor skill. It gives full consideration to the human body and the ability of clothing to reconcile and comfort" [24]. The principles of ergonomics are considered in apparel outline for clothing items [25] for various specific occupational uses, as well as for people with disabilities [26-28]. Other studies have reported that "clothing ergonomic design is critically important in active sporting activities for human thermal comfort" [29, 30].

\subsection{Ergonomic wear comfort}

Ergonomic comfort of clothing is most important for sportswear and personal PC to support the wearer during different activities. The most important requirements for ergonomic wear comfort that the textile should possess are allowing freedom of movement, reducing load/strain, and maintaining the body shape [31, 32]. These are predominantly characterized by the garment's fit design and pattern construction and can be influenced by the elasticity or the stretchability of the material [33]. Ergonomic considerations dictate that the mechanical characteristics of clothing match the motion, degree of freedom, range of motion (ROM) and force, and the moment of human joints. The shape and fit of the garment vis-à-vis the human body, as well as the pressure and friction exerted by the garment on the body, are some of the factors that affect this aspect [34].

One of the basic functional requirements for all types of sportswear is the wear comfort, which is the global comfort during wearing; it includes thermal properties, passive touch (or fabric touch [to the skin], and not hand of textile) and ergonomic comfort. Wear comfort is important for players as it may enhance performance by providing suitable physiological conditions in all climatic extremities [35]. Concerning ergonomic wear comfort, in active sports such as running, skin extension and contraction take place due to the high degree of body movement, which alters the corresponding body measurements $[36,37]$. Sportswear clothing should not restrain these movements; else, discomfort will be created due to undesired garment pressure. Body fabric is commonly used in tight-fit running shorts, which provide the desired shape and size with adequate room for body movements [38-41].

\subsection{Why ergonomic wear comfort?}

Providing comfort in clothing for the moving body is a complex task. Interactions among body sizes and shapes, physiological variations, material properties, design choices, environmental challenges, and activities are exponential in their number. The impact of clothing on the comfort and performance of individuals at work or sport is of particular importance. Industrial and sport $\mathrm{PC}$ is governed by protection requirements, and sport clothing is generally selected on the basis of performance and comfort [42]. The impact of PC on performance is determined by the nature of the work or sport, the metabolic rate required, the ambient environment, and the characteristics of the PC [43]. The ergonomic requirements and ergonomic aspects according to the degree of importance for industrial PC users are as follows: (1) proper fit or sizing; (2) reduction of hotness and improving ventilation through pattern, design and material selection; (3) reduction of weight and reduction in obstruction to work; and (4) ease of mobility [44].

Ergonomics and sports science are closely tied together when taking human performance into consideration. Both workers and athletes have to optimize the level of their performance in relation to the external demands [45]. There are many industrial situations where workers are required to wear personal PC and equipment (PPE), e.g., firefighters, chemical workers, coldstore workers, army personnel and those working in the steel and forestry industries. Although this $\mathrm{PC}$ may provide protection from the primary hazard, e.g., heat or chemicals, it can also create ergonomic problems [46-48]. In recent years, many PPE product standards have been introduced. These have helped to improve the quality of the PC and thus have increased the safety of the workers. There are important side effects to PC, and typically with increasing protection requirements, the ergonomic problems typically increase. Often, the main problem is the added load on the body in terms of weight. Moreover, reduced mobility due to garment stiffness reduces the freedom of movement and may increase the risk of falls or getting caught in machinery. As a result, the PPE may actually reduce safety rather than improving it, especially after the PPE has been worn for a certain duration. As a consequence, the user may refrain from wearing the necessary protection.

For instance, when performing a task in a fire, the heat and perspiration generated from the body become trapped inside the PC. The heat and moisture thus generated result in heat stress and physical fatigue of the firefighter, which hinders their work. Therefore, the clothing design and material layers for firefighter suits must be chosen carefully to balance protection and comfort, with emphasis on choosing the lightest and the most breathable system that provides acceptable thermal insulation [43, 49]. Therefore, reduced thickness, lower weight and lower stiffness should positively affect comfort, thermal resistance, evaporative resistance and total heat loss; however, insulation from heat and fires must remain high and runs counter to the methods used to improve comfort while working. An open structure of the fabric may lower evaporative resistance and increase total heat loss through evaporative cooling $[50,51]$. Considering the physical movement of humans, many manufacturers are convinced of the need to include vents in some of their outdoor athletic apparel to address thermal burden and/or moisture issues [52].

\subsection{Attributes for sportswear and PC}

i. Allowing freedom of movement/improving body movement: This enables ergonomic wear comfort to improve due to the garment's pattern, fitness, and the stretchiness; lower weight, reduced thickness and less stiffness; and recovery of the materials. These factors play a significant role in affecting the body movement. Especially, elastic textiles can improve the ease of movement of clothing and, thus, the ergonomic 
wear comfort $[53,54]$. In sport activities, there is a dynamic interaction between the garment and the body: this includes thermophysiological, tactile, and psychological interaction. These are all dependent on various properties of the fabric and garment, as well as on environmental conditions and the type and level of activity of the wearer [55-57]. Today's stretchable garments for sports and outdoor wear play an important role in optimizing an athlete's performance by providing freedom of movement, maximizing comfort, minimizing the risk of injury or muscle fatigue, and reducing friction or drag [58, 59]. A wellfitted sport garment must not interfere with, impede, or restrict the body movement relative to the end use. For instance, it is impossible to perform any exercise while the garment restricts body movements. On the contrary, the garment must enable the free exercising of the sport activity and the performance of the ROM expected of him or her.

ii. Reducing load/strain: Stress, training, fatigue, load, and environmental conditions have an influence on the evaluation of human performance and the degree of freedom. Uneven weight distribution of the garment and heavy loads can create discomfort and an irregular strain on the musculoskeletal system, in addition to reducing the ergonomics of a gesture [60, 61]. It is true that functional and protective fabrics are superior in their hand properties (feel, stiffness, drape, and bulk) [6264]. The aim should be to provide a lighter garment with a better-tailored and comfortable fit, as this would contribute to higher garment functionality and improved ergonomics. At the same time, a lighter fabric would allow some moderate gains in reducing the heat load. For military $P C$, the research and development process has developed several new protective material systems and incorporated design features into a uniform concept targeted specifically at the reduction of thermal burden when the individual protective equipment is worn. Reducing thickness, minimizing weight, and lowering stiffness should positively affect comfort, thermal resistance, evaporative resistance, and total heat loss.

iii. Maintaining the body shape: Ergonomic clothing relates for the most part to wearing attire, especially to apparel developed to suit the curvature and the movement and development of the human body. This enables increase in user comfort, as the article of clothing is highly wearable. The making of clothing to which aesthetically appreciable curvature is applied inspires people to buy the product [15, 65-67].

iv. Mechanical properties: Mechanical properties of the fabric can be important determinants of comfort and ergonomics in PC $[68,69]$. Mechanical properties such as tactile stiffness of the material components contribute to the flexibility and comfort of PC designed for emergency responders.

v. Breathability: Moisture management property is an important aspect of any fabric meant for active sportswear and $P C$, which decides the comfort level of that fabric. Every human being sweats during different kinds of activities. An important feature of any fabric is how it transports this water out of the body, so as to make the wearer feel comfortable [70, 71].

\section{Measurement of ergonomic wear comfort}

A standard method for the evaluation of ergonomic comfort, specifically for sportswear, does not exist, yet development of testing standards for each type of garment in terms of the comfort, fit, and function according to activities and movements expected for the end use could help manufacturers in evaluating and improving the comfort of the garments. Furthermore, assessing the comfort of PC is a complex task as several of the aspects involved are highly subjective and associated with specific activities. Ergonomic assessments for PC have not been widely applied, partly because the required protocols generally can involve elaborate human subject requirements and use subjective methods of evaluation. American Society for Testing and Materials (ASTM) F1154 is an example of an available standardized test [72] for qualitatively evaluating the comfort, fit, function, and integrity of a chemical protective ensemble. Procedural alternatives to assess the impact of a protective outfit on the capability of test subjects performing routine work assignments are additionally described in this approach. This standard can be adapted for various sorts of protective ensembles and functionalities.

However, the selection of appropriate parameters, test procedures, equipment, and facilities required for the human textile comfort response protocols is of critical importance for the assessment of the comfort and protective properties of advanced fabrics and assemblies. This section reviews the fundamental concepts of measuring clothing attributes related to ergonomic wear comfort for functional clothing associated with changes in physiological, psychological, physical, and mechanical perceptions. These are investigated through contemporary methodology and approaches, such as the contribution of skin model, thermal mannequin, biomechanical analysis, mathematical models, as well as subjective and objective modes of assessment performed with diverse instruments.

\subsection{Measurement of freedom of movement}

Human performance can most certainly be impaired by apparel with poor fit, restricting factors such as ROM, reach, and manual dexterity. The ergonomic principles of optimizing fit; reducing weight of the garments or garment assembly; and altering the physical stress of performing a task through innovative garment design remain central to optimizing human performance. However, the garment has to fit the wearer without restricting the full ROM. It needs to be comfortable and aim not to abrade the skin. Ergonomic considerations dictate that the mechanical characteristics of clothing match the motion, degree of freedom and ROM, as well as the force and moment of human joints.

Fit testing of clothing prototypes on human fit models is common practice in the apparel industry to refine patterns before clothing is manufactured [73-75]. Fit models sit, walk, and, in the case of active wear, test the prototype by engaging in the sport for which it is designed. In the research community, both controlled fit studies and wear tests that challenge the garments with actual working conditions are common practice 
in the design and testing of functional apparel. Studies using instrumented mannequins are also common.

Development of robotic testing devices that duplicate the joint motion and ROM of a human, with the movements internally inducted, could result in a reliable laboratory-based test of clothing ensemble performance for the required ROM [76]. $\mathrm{ROM}$ is an important performance measure for workers wearing personal PC. It is frequently used to compare competing garment designs and to assess worker mobility [77]. Motion studies evaluate the wearer's ability to perform repetitive movements and typically measure ROM or reach capability.

A range of experimental models have been used to objectively assess mobility restriction caused by PC. Initially, a test battery of simple movements and measurements, which could be performed with minimal training and equipment, was developed [78]. More recent studies have measured encumbrance using goniometers, Leighton flexometer, a potentiometer-driven microcomputer system [79, 80], and inclinometer [81].

Among the measures of mobility restriction, ROM has two obvious advantages. First, ROM can be objectively quantified in terms of joint angles or reach distances. Reach distances often involve more complex motions, with movement occurring in multiple planes and involving multiple joints, whereas joint angle measurement is well suited for use in the laboratory. A second advantage of using ROM measurements is that they can be taken with instruments that are relatively unsophisticated and easy to use. The ease of motion can be assessed through wearer trials by performing a series of practical activities based on the wearer's body movement [82]. Figure 2 shows the distribution of electro-goniometers on the body of the subjects.

The effects of different garments or garment assemblies on the ROM have been studied using a variety of goniometers and flexometers, none of which require calibration, installation or set-up. Dorman and Havenith $[56,57]$ showed the effect of PC on mobility, and Huck tested different designs of firefighter turnout gear [85]. The electrogoniometer system uses strain gages mounted within a protective spring. End blocks are attached to the subject's skin. The strain gages in the blocks are connected to the data logger, and thus, the information about the movement is collected [83].

\subsection{Influence of the ergonomic wear comfort on the thermal wear comfort}

Changes to improve the ergonomic wear comfort may influence the thermal comfort, which requires measurement of the thermal properties to verify whether they are negatively influenced or not [86]. This can be achieved through human testing of the ensembles or manikin testing. For certain PPEs such as those for firefighters, the ergonomic wear comfort is also closely linked to the thermal comfort in the sense that ergonomic changes are done to improve the heat balance in the protective suit.

The thermal wear comfort of the textile material is dependent on moisture regain, porosity, density and air permeability characteristics of the fabric. These characteristics also have an effect on the ergonomic wear comfort property of the fabric. The fabric weight increases as the amount of fibers in the fabric increases per unit area, which will reduce the amount of air transport in the fabric. This is directly related to the amount of air entrapped in the fabric. In this case, the thermal property of the fabric will have higher conductivity than the entrapped air [87]. Therefore, we can conclude that the fabric structure of textile materials has an effect on moisture regain, porosity, density, and air permeability property, and this will have an effect on the thermal and the ergonomic wear comfort property of textiles.

Evaporative resistance and thermal insulation of clothing can be measured directly in humans. For example, Taylor et al. [88] developed a method to determine the effective evaporative resistance of clothing in vivo and concluded that the method, in combination with partition calorimetry, can determine the resistances of clothing with dry and wet heat loss for both resting and working subjects [89]. The evaporative resistance from the evaporative heat loss and vapor pressure at the skin surface

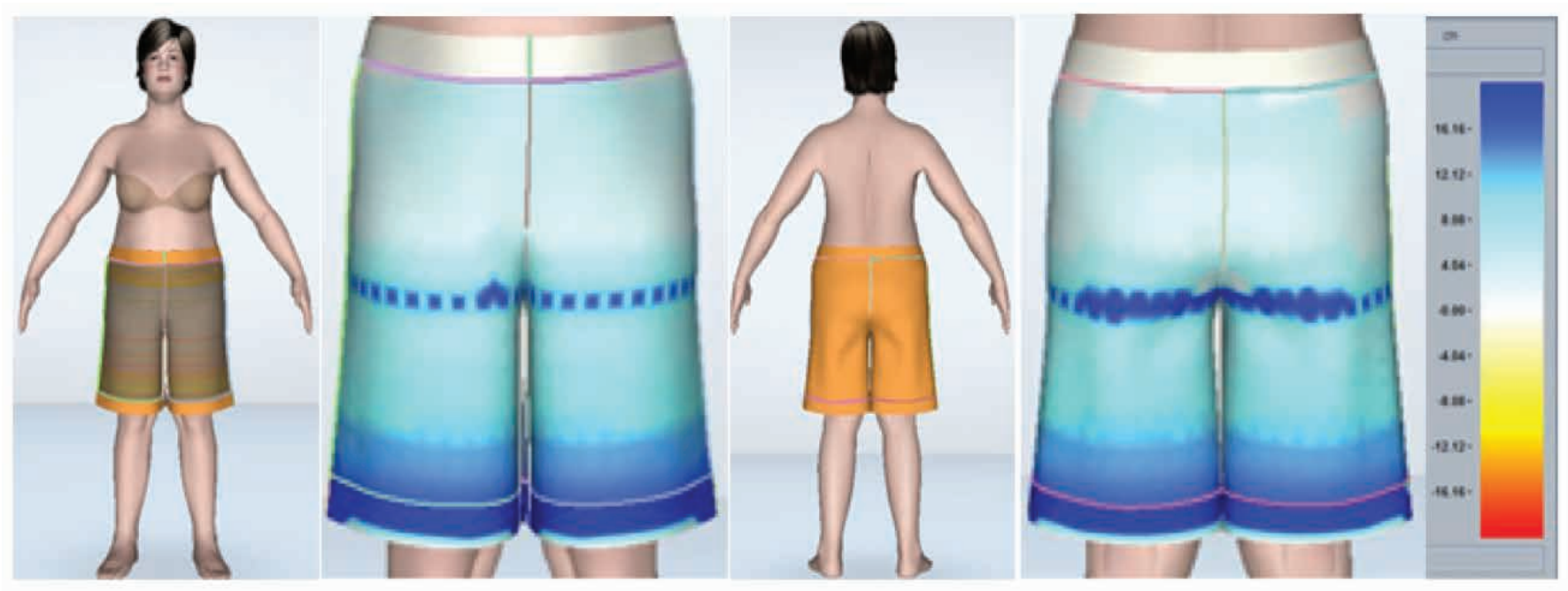

Figure 2. Distribution of electrogoniometers on the body of the subjects (copied from Ciesielska-wróbel et al. [83]). 


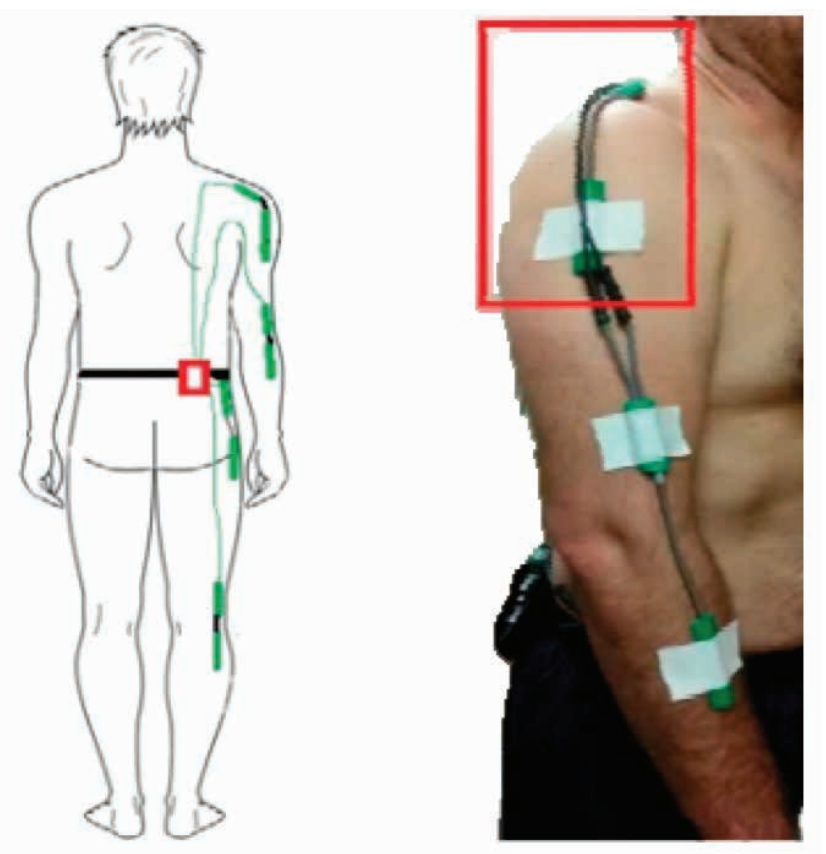

Figure 3. Distribution of the electrogoniometers on the body of the subjects (copied from Ciesielska-wróbel et al. [83]).

and in the environment is estimated and used to compare the evaporative cooling capacity of PC ensembles [90].

In order to accurately determine the evaporative resistance and thermal insulation of clothing, thermal manikins have been developed since the 1940s [91, 92]. In terms of development, thermal manikins can be grouped into four types [93, 94]. The first is the standing (viz., nonwalking) and nonperspiring type $[95,96]$. The second is the movable (viz., walking), but nonperspiring type, such as the copper manikin "Charlie" in Germany [97]. The third type is the nonsweating manikin, but sweating is simulated by wetted skin. This type of manikin is currently used by Holmer in Sweden, McCullough in the USA, and Havenith in Britain. The fourth type is the perspiring forms of types 1 and 2, which adds a lot of complexity, such as "Taro" in Japan [98], "Kem" in Japan [99], "Coppelius" in Finland [100], "Sam" in Switzerland, and "Walter" in Hong Kong [101].

Thermal manikin systems are perfect for a broad range of clothing and environmental testing. The degree of thermal comfort depends greatly on the local environment [102]. Human beings usually use different types of clothing and respond differently to heat transfer from different body areas. The various types and amounts of clothing that manikins use today make comparative interpretation of results from different manikins/methods very complicated. In order to facilitate comparison of results, the methods should be independent both of the manikin used and the clothing worn. The total heat transmitted through clothing is commonly considered the sum of the dry heat transfer and the evaporative heat transfer, and it is measured under nonperspiring conditions, e.g., a dry thermal manikin is frequently used to calculate the dry heat transfer when the body is perspiring or even sweating heavily [102104]. There is also a possibility of error in the measurement of water vapor resistance. In order to ascertain how perspiration or sweating affects the clothing thermal insulation during dry heat transfer, a novel perspiring fabric thermal manikin is used to measure the clothing thermal insulation in cases of both little perspiration and more perspiration.

\subsection{Fabric physical measurement through wearer trials}

Modern textile products make their most valuable contribution to the well-being of humankind, but their acceptability depends upon the permitting of thermal comfort and a satisfactory "feel" in the area of fabric-skin contact. The main purpose of the wearer trial is to gather information from the respondent at the garment level [105-107]. The principle of the user performance trial is to investigate clothing while in actual use, hence providing practical information. This will involve identifying a sample of users of the clothing and observing the properties over a period of time representing realistic conditions. Questionnaire techniques and possibly some physiological measures can be used [108, 109]. Therefore, wearer trial is an important technique for clothing comfort research, although the process tends to be expensive and time consuming and the results tend to be less reproducible and consistent. This method has been used for evaluating moisture, as well as the ergonomic, thermal, tactile, and esthetic comfort. Wearer trials can also be designed to obtain some objective sensory measurements under different wearing conditions that are relevant to the behavior of the knitted underwear [110]. During the test, subjects are asked to wear the garments under study; then, each subject has to rate the garment on selected comfort sensation. Various sensory descriptors are generated from the responses of the respondents, and the testing conditions are selected to maximize the perceptions of various sensations. Attitude scales are designed to obtain various sensory responses for a particular item/garment.

According to predetermined protocols, wearer trials are conducted under controlled testing conditions, and the data is collected and analyzed. The analysis of the firsthand physiological data gathered from wearer trials can provide insight into the ergonomic design of clothing.

\subsection{Measurements of physiological parameters in human wear textiles in the context of Ergonomics}

Different researchers have worked on direct sensing from the human body using different methods. This includes the hydrostatic pressure-balance method [111], pneumatic pressure sensors [112-114], resistive pressure sensors [115, 116], elastic optical fiber pressure sensors [117,118], and capacitive pressure transducers [119]. Owing to the relative stability and accuracy, the most popularly used types of pressure sensing devices are the Air-pack sensor developed by AMI Techno Co., Ltd (Tokyo, Japan) [120] and the flexiforce pressure sensor developed by Tekscan, Inc. (Boston, MA, USA). However, insertion of the sensor between fabric and skin could bend the sensor and cause discrepancies in the measurements.

The "garment pressure" is one of the important features used to evaluate the performance in terms of comfort, function, and security of compression garment. Pressure from compression garment onto human body should be in an appropriate range. 


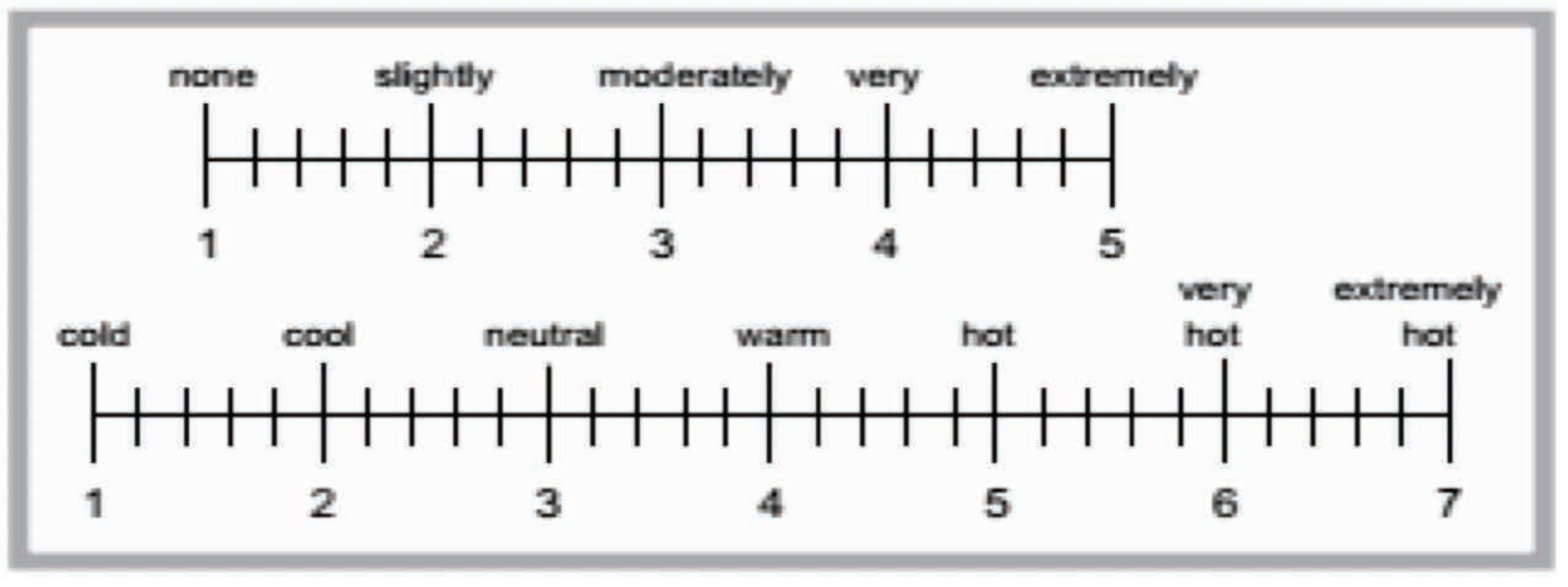

Figure 4. Subjective rating scales for subjective sensations (copied from Wu et al. [109]).

Therefore, it is still important to build a scientific and precise evaluation system for pressure comfort. Compression was examined by Yongrong Wang et al. [61] using the Air-pack type contact pressure sensor (AMI Techno Co., Ltd) for sensory tests, and a novel stretchable compressive belt was designed and developed, which was used to control the pressure applied on separate body parts by the belt's extension and contraction [121].

Flexiforce pressure sensor is constructed of two layers of polyester substrate; conductive silver is applied on each layer, followed by a layer of pressure-sensitive ink. Sensors respond to single-point force loads over a sensing area of $9.53 \mathrm{~mm}$ with claimed operating range $0-1 \mathrm{lb}$. This has found applications in many fields, especially suitable for medical applications for compression therapy: the application of persistent pressure on the surface of a limb, most often a leg, is a widely accepted clinical treatment for chronic venous disorders due to their thin and flexible construction and ability to operate at low pressures [122].

I-Scan ${ }^{\mathrm{TM}}$ pressure mapping sensor is a versatile pressure mapping system developed by Tekscan, Inc. , which provides accurate measurements of both force and pressure between two surfaces. The Tekscan system is easy to use and very dependable and has helped to improve ergonomic advantages. The interface pressure data collected offers vital information and insight to enhance product design, manufacturing, quality, and research [123].

Venkatraman and Taylor [29, 124] investigated the pressure profile of compression garments for cyclist participants using Tekscan pressure sensors on various points (lower limb). Trial wear is required to investigate user perceptions for the fit, comfort, ease of wear, tactile sensation, and overall satisfaction. Hence, suitable inferences drawn from these findings enable the ascertainment of the performance of compression garments and aid in further development [124].

Accuracy and reproducibility of direct measurements from human subjects are difficult to achieve because the sensors are readily affected by noise due to body movement. On the other hand, Microlab Electronica have developed a portable digital gauge called PicoPress to be used to measure the pressure exerted by a bandage or garment for medical purposes. The instrument utilizes a circular transducer made out of an ultrathin biocompatible material in which a known quantity of air is inserted. The transducer is placed between the skin and clothing/bandage.

During sport activities, compressive textiles reduce wobbling masses, muscle vibration, and swelling, and even the skin is influenced by the pressure of the compression textile, as claimed by Sioson et al. [126]. New properties require new laboratory test methods to determine the function and its effect. However, sensorial comfort is difficult to predict as it involves different factors. Besides, ergonomic comfort, sometimes also called aesthetic comfort, can be tested with different objective methods. One of the traditional methods is to measure the space between the body and the clothing and then calculate the fitting index.

\subsection{Pressure comfort measurement: numerical simulation of garment pressure}

Modeling and simulation of textile fabrics represents an important field of scientific research. Interdisciplinary cooperation of scientists in the fields of physics, mechanics, mathematics, and informatics is necessary for the simulation and prediction of textile properties and behavior. Modeling tools are useful for estimation of skin sensorial comfort, and further research activities are required [127].

Researchers have developed a mathematical model of geometric nonlinearity based on the theory of contact mechanics to simulate the dynamic garment pressure distribution on a 3D human body during wear [128]. The model was able to illustrate the dynamic garment pressure distributions when a rigid female body wearing a set of perfect-fitting garments is in motion. The numerical computational results show that the model can predict, without the actual production of the garments, the dynamic mechanical behavior of garments during wear, including the garment deformation, the garment pressure, the internal stresses in the garment, and the effects of the garment's 

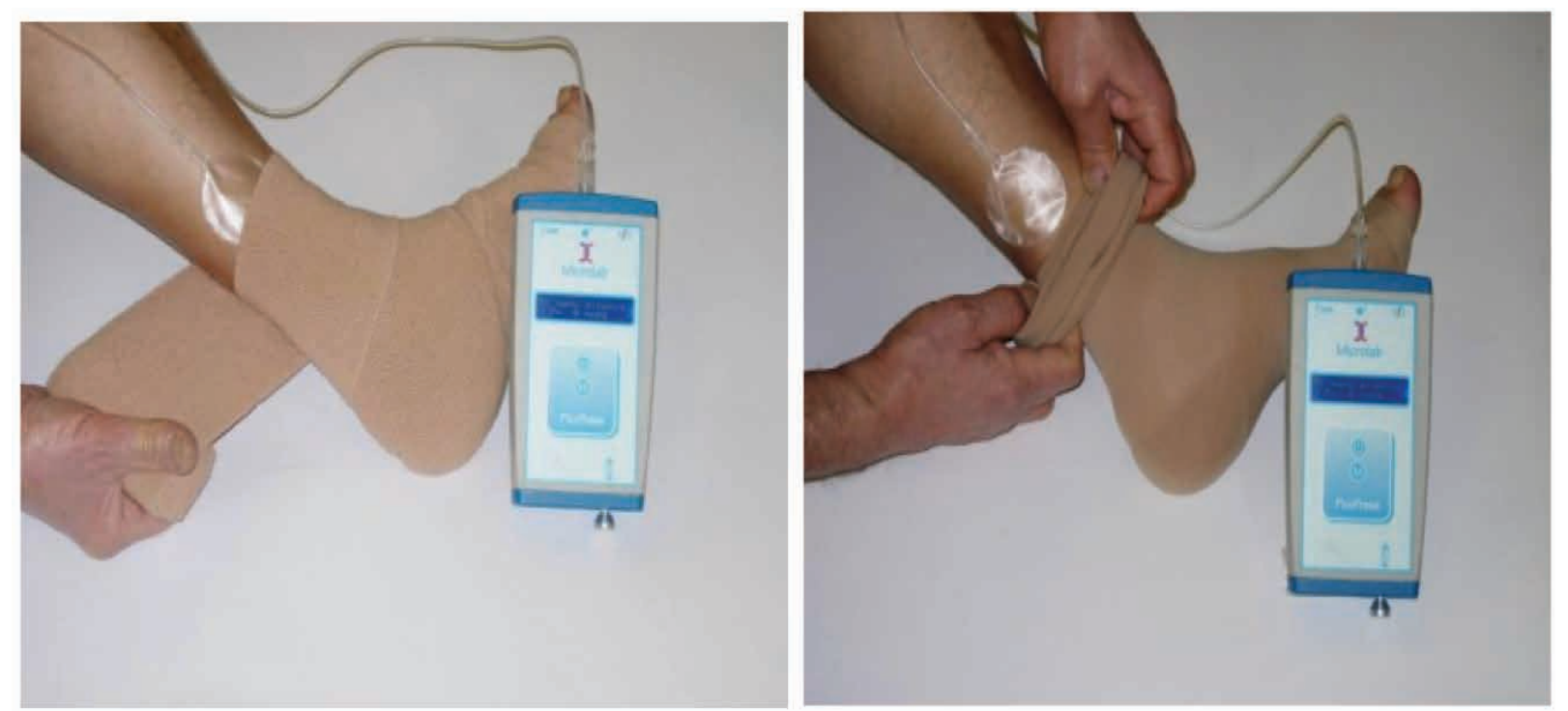

Figure 5. Making measurements: connect the sensor to PicoPress (copied from Electronica [125]).

weight and inertia force on the dynamic wearing process [128, 129]. However, as the human body is assumed to be rigid, the dynamic mechanical interactions between the body and the garment cannot be simulated realistically, especially the deformation of the human body and the pressure distribution under the skin and soft tissues.

\subsection{Subjective assessment coupled with objective measurement of pressure comfort}

There are many works that combine both objective and subjective systems for measuring clothing comfort as it is believed that objective systems do not ensure a full representation of thermophysiological, sensory/tactile, and movement comfort due to their lack of a human element or their focus on a single property [130]. The objective methods provide quantified results, but in some cases, such quantified results are quite far from the real perception of $H C[130,131]$.

Clothing comfort is very subjective. Evaluation of pressure comfort must combine the predicted pressure and the sensation index from a large volume of experiments involving wear trials. It needs much work on psychological evaluation of garment pressure, from which a series of psychophysical models are developed based on the investigation of the relationship between objective stimuli and psychological perceptions and the investigation of the relationship between the predictions and the objective measurements. It is believed that subjective assessment is a complex synthesis of many kinds of psychological and physiological response of individuals. Consequently, the subjective responses of wearers are not only decided by the physical properties of garments but also by the wearing habits and experiences of wearers. Therefore, questionnaire design is critical for the rating of subjective sensations. Factor analysis is usually applied to clarify the effect of factors, such as different garment sizes and fabrics with different extensibilities. Regression analysis of clothing pressure, fabric extensibility, and garment fitness is used to establish the relationship between subjective assessment and objective physical factors [105, 132, 133].

\section{Conclusions}

We have presented an overview of contemporary methodologies and approaches for measuring ergonomic wear comfort, including objective and subjective techniques. Standard methods for evaluation of comfort for each type of garment in terms of the wear comfort, fit, and function according to activities and movements do not exist. We are convinced that this goal can only be achieved by addressing freedom of movement, reducing load/strain, evaluating how the garment maintains the body shape, as well as the analyzing the mechanical properties, breathability, smoothness and softness. We consider it relevant that the assessment of ergonomic wear comfort requires a multidisciplinary approach. There are four main techniques to measure wear comfort: objective measurements, subjective evaluation, a combination of objective and subjective techniques, and computer modeling of human-textile interaction. With objective measurement methods, the repeatability of results is excellent and these provide quantified results, but in some cases, such quantified results are quite different from the real perception of $\mathrm{HC}$. Though the significance of objective measurement is becoming popular, there are many questions related to its accuracy in predicting comfort. The real comfort of clothing is measured through subjective testing, which relates to the direct measure of the individual's opinion by the use of psychological scaling techniques. The subjective testing of comfort involves complicated processes in which subjective perception is formed from a number of stimuli related to clothing and the external environment as they are being communicated to the brain through sensory responses. It can be done at the fabric as well as the garment level, using various types of measurement scales and different types of scaling techniques, such as wear trial technique. Subjective analysis of comfort, however, is less reliable than objective analysis; as human subjects vary among themselves, may not be in the exact same condition in different timelines, and are less reliable than controlled testing equipment. Therefore, a combination of objective and subjective measuring techniques with respect to the various approaches to model comfort will yield the best validity. 


\section{Acknowledgements}

This paper was supported by the HGPP project (International University Partnership Services for the Establishment of Postgraduate Programs in Ethiopia) funded through GIZ GmbH under a grant number 11.2216.7/002.01.

\section{References}

[1] Li, Y. (2001). The science of clothing comfort. Textile Progress, 31(1-2), 1-135,.

[2] Das, A., Alagirusamy, R. (2010). Science in clothing comfort. Woodhead Publishing Limited (Cambridge).

[3] Liu, R., Lao, T. T., Xiao Wang, S. (2013). Technical knitting and ergonomical design of $3 D$ seamless compression hosiery and pressure performances in vivo and in vitro. Fibers and Polymers, 14(8), 1391-1399.

[4] Velani, N., Wilson, O., Halkon, B. J., Harland, A. R. (2012). Measuring the risk of sustaining injury in sport a novel approach to aid the re-design of personal protective equipment. Applied Ergonomics, 43(5), 883-890.

[5] Song, G. (2011). Improving comfort in clothing, (1st ed.). Woodhead Publishing Limited (Cambridge).

[6] Bhatia, D., Malhotra, U. (2016). Thermophysiological wear comfort of clothing: an overview. Journal of Textile Science and Engineering, 6(2), 250.

[7] Junyan, H.U. (2006). Characterization of sensory comfort of apparel product. Hong Kong Polytechnic University.

[8] Bartels, V. T. (2006). Physiological comfort of biofunctional textiles. Current Problem in Dermatology, 33, 51-66.

[9] Senthil Kumar, R. (2012). Textiles in sports and leisure. Asian Textile Journal, 21(9), 44-49.

[10] Kothari, V. K. (2006). Thermo-physiological comfort characteristics and blended yarn woven fabrics. Indian Journal of Fibre and Textile Research, 31(March), 177186.

[11] Pamuk, O. (2008). Clothing comfort properties in textile industry. New World Sciences Academy, 3(1), 1-6.

[12] Kilinc-Balci, F. S. (2011). Testing, analyzing and predicting the comfort properties of textiles. In: Song, G. (Ed.). Improving comfort in clothing. (1st ed.). Woodhead Publishing Limited (Cambridge), pp. 138-162.

[13] Gupta, D. (2011). Design and engineering of functional clothing. Indian Journal of Fibre and Textile Research, 36(4), 327-335.

[14] Goonetilleke, R., Karwowski, W. (2016). Advances in physical ergonomics and human factors. In: International Conference on Physical Ergonomics and Human Factors, Florida, USA, July 27-31, 2016, p. 489.

[15] Li, Y. I., Wong, A. S. W. (2006). Clothing biosensory engineering. (1st ed.). Woodhead Publishing Limited (Cambridge, England).

[16] Wang, J., Agarwal, T.-K., Liu, K., Kamalha, E. (2016). Optimization design of cycling clothes' patterns based on digital clothing pressures. Fibers and Polymers, 17(9), 1522-1529.

[17] Gupta, D., Zakaria, N. (2014). Anthropometry, apparel sizing and design. (1st ed.). Woodhead Publishing Limited (Cambridge, England).
[18] Patricia Dolez, V. I., Olivier, V. (2018). Advanced characterization and testing of textiles. Elsevier Ltd. (Cambridge).

[19] Duffield, R., Cannon, J., King, M. (2010). The effects of compression garments on recovery of muscle performance following high-intensity sprint and plyometric exercise. Journal of Science and Medicine in Sport, 13(1), 136-140.

[20] Colovic, G. (2014). Ergonomics in the garment industry. (1st ed.). Woodhead Publishing Limited (Cambridge).

[21] Scataglini, S. (2017). Ergonomics of gesture: effect of body posture and load on human performance.

[22] Mital, S. K. A., Kilbom, A. (2000). Ergonomics guidelines and problem solving. (1st ed., vol. 1). Elsevier Science Ltd.

[23] Reilly, T. (2010). Ergonomics in sport and physical activity: enhancing performance and improving safety, no. 9.

[24] Jin, Z., Chen, D., Yang, Y. (2015). Research of effect of ergonomics on athletic shoes and costume design project. In: International Conference on Education Technology, Management and Humanities Science, 2015, Etmhs, pp. 147-150.

[25] Moritz, E. F., Haake, S. (2006). The role of engineering in fatigue reduction. The Engineering of Sport 6, 3(January), 1-440.

[26] Pan, N., Sun, G. (2011). Functional textiles for improved performance, protection and health. Woodhead Publishing Limited (Cambridge, England).

[27] Kumar, S. (2005). Perspectives in rehabilitation ergonomics. Taylor \& Francis (London).

[28] Vianna, C., Quaresma, M. (2015). Ergonomic issues related to clothing and body changes of the new elderly women. Procedia Manufacturing, 3(Ahfe), 5755-5760.

[29] Venkatraman, P., Tyler, D. (2016). Applications of compression sportswear. In: Hayes S. G., Venkatraman, P. (Eds.). Materials and technology for sportswear and performance apparel. (1st ed.). Taylor \& Francis Group (New York), pp. 171-200.

[30] Jin, H. (2010). Assessment of men's tennis clothing: movement and aesthetic analysis. Washington State University.

[31] Chunyan, Q., Yue, H. U. (2015). Design of outdoor sports monitoring function cycling Jerseys. European Journal of Business and Social Sciences, 4(2), 180-189.

[32] De Raeve, A., Vasile, S. (2016). Adapted performance sportswear. In: Proceedings of the 7th International Conference on 3D Body Scanning Technol. Lugano, Switzerland, 30 Nov.-1 Dec. 2016, pp. 9-15.

[33] Hassan, M., Qashqary, K., Hassan, H. A., Shady, E., Alansary, M. (2012). Influence of sportswear fabric properties on the health and performance of athletes. Fibres and Textiles in Eastern Europe, 4(93), 82-88.

[34] Bringard, A., Perrey, S., Belluye, N. (2006). Aerobic energy cost and sensation responses during submaximal running exercise - Positive effects of wearing compression tights. International Journal of Sports Medicine, 27(5), 373-378.

[35] Hu, J. (2016). Active coatings for smart textiles. Elsevier Ltd (Cambridge).

[36] Shishoo, R. (2005). Textiles in sport. Elsevier Ltd (Cambridge, England). 
[37] Wang, P., McLaren, J., Leong, K. F., and Des Ouches, P. J. (2013). A pilot study: Evaluations of compression garment performance via muscle activation tests. Procedia Engineering, 60(65), 361-366.

[38] Holschuh, B., Obropta, E., Buechley, L., Newman, D. (2012). Materials and Textile architecture analyses for mechanical counter-pressure space suits using active materials. In: AIAA Space 2012 Conference \& Exposition, p. 18.

[39] Peiyuan, Z. (2013). Biofunctional engineering of seamless sportswear. The Hong Kong Polytechnic University.

[40] Geršak, J. (2014). Wearing comfort using body motion analysis. Woodhead Publishing Limited.

[41] Ashdown, S. P. (2011). Improving body movement comfort in apparel. In: Song, G. (Ed.). Improving comfort in clothing. (1st ed.). Woodhead Publishing Limited (Cambridge), pp. 278-302.

[42] Bishop, P. A. (2014). Ergonomics and comfort in protective and sport clothing: a brief review. Journal of Ergonomics, S2(2).

[43] Chung, G. S., Lee, D. H. (2005). A study on comfort of protective clothing for firefighters. Environmental Ergonomics, 3, 375-378.

[44] Konarska, M., Sołtynski, K., Sudoł-Szopińska, I., Chojnacka, A. (2007). Comparative evaluation of clothing thermal insulation measured in a thermal manikin and on volunteers. Fibres and Textiles in Eastern Europe, 15(2), 73-79.

[45] Madeleine, P. (2010). On functional motor adaptations: From the quantification of motor strategies to the prevention of musculoskeletal disorders in the neck-shoulder region. Acta Physiologica, 199(Suppl. 679), 1-46.

[46] Williams, W. J., Roberge, R. J., Kim, J.-H., Coca, A. (2011). Subjective perceptions and ergonomics evaluation of a liquid cooled garment worn under protective ensemble during an intermittent treadmill exercise. Ergonomics, 54(7), 626-635.

[47] Mattila, H. R. (2006). Intelligent textiles and clothing. Woodhead Publishing Limited \& \& CRC Press LLC (Cambridge, England).

[48] Madeleine, P., Samani, A., de Zee, M., Kersting, U. (2011). Biomechanical assessments in sports and ergonomics. Theoretical Biomechanics.

[49] O'Brien, C., Blanchard, L. A., Cadarette, B. S., Endrusick, T. L., Xu, X, et al. (2011). Methods of evaluating protective clothing relative to heat and cold stress: Thermal manikin, biomedical modeling, and human testing. Journal of Occupational and Environmental Hygiene, 8(10), 588-599.

[50] Havenith, G., Holmér, I., Parsons, K. (2002). Personal factors in thermal comfort assessment: Clothing properties and metabolic heat production. Energy Building, 34(6), 581-591.

[51] Wang, F. (2014). Clothing evaporative resistance: its measurements and application in prediction of heat strain. Department of Design Sciences, Lund University (Sweden).

[52] Bartels, V. T. (2011). Improving comfort in sports and leisure wear, no. 2007. Elsevier Masson SAS.

[53] Korff, R. (2002). Ergonomic garments.

[54] Ozdil, N., Anand, S. (2014). Recent developments in textile materials and products used for activewear and sportwear. Electronic Journal of Textile Technology, 8(3), 68-83.
[55] Lovell, D. G., Mason, D. I., Delphinus, E. M., Mclellan, A. C. P. (2011). Do compression garments enhance the active recovery process after high-intensity running? The Journal of Strength and Conditioning Research, 25(12), 32643268.

[56] Dorman, L. E., Havenith, G. (2007). Examining the impact of protective clothing on range of movement. Loughborough University (Loughborough).

[57] Dorman, L., Havenith, G. (2007). The effects of protective clothing and its properties on energy consumption during different activities - literature review. European Journal of Applied Physiology, 105, 463-470.

[58] Liu, R., Little, T. (2009). The 5Ps model to optimize compression athletic wear comfort in sports. Journal of Fiber Bioengineering Informatics, 2(1), 41-52.

[59] Hes, L. (2008). Non-destructive determination of comfort parameters during marketing of functional garments and clothing. Indian Journal of Fibre and Textile Research, 33(3), 239-245.

[60] Ibrahim, F., Usman, J., Yazed, M., Norhamizan, A. (2018). 2nd International Conference for Innovation in Biomedical Engineering and Life Sciences. In: 2nd International Conference for Innovation in Biomedical Engineering and Life Sciences, 2018, vol. 67, pp. 10-13.

[61] Wang, Y., Wu, D., Zhao, M., Li, J. (2014). Evaluation on an ergonomic design of functional clothing for wheelchair users. Applied Ergonomics, 45(3), 550-555.

[62] Black, S., Kapsali, V., Bougourd, J., Geesin, F. (2005). Fashion and function - factors affecting the design and use of protective clothing. Textiles for Protection, Woodhead Publishing (Cambridge), pp. 60-89.

[63] Nasir, S., Troynikov, O., Quintero Rodriguez, C. (2018). Body mapping as a method for design and engineering of functional clothing. In: Textile Bioengineering and Informatics Symposium Proceedings, 2018, pp. 364-369.

[64] Arpinar-Avsar, P., Birlik, G., Sezgin, Ö. C., Soylu, A. R. (2013). The effects of surface-induced loads on forearm muscle activity during steering a bicycle. Journal of Sports Science and Medicine, 12, 512-520.

[65] Belbasis, A., Fuss, F. K. (2015). Development of nextgeneration compression apparel. Procedia Technology, 20(July), 85-90.

[66] Slater, K. (1977). Comfort properties of textiles. Textile Progress, 9(4), 1-71.

[67] Cao, M., Li, Y., Guo, Y., Yao, L., Pan, Z. (2016). Customized Body mapping to facilitate the ergonomic design of sportswear. IEEE Computer Graphics and Applications, 36(6), 70-77.

[68] Bassett, R. J., Postle, R., Pan, N. (1999). Experimental methods for measuring fabric mechanical properties: a review and analysis. Textile Research Journal, 69(11), 866-875.

[69] Dadi, H. H. (2010). Literature over view of smart textiles. University of Borås (Sweden).

[70] Bedek, G., Salaün, F., Martinkovska, Z., Devaux, E., Dupont, D. (2011). Evaluation of thermal and moisture management properties on knitted fabrics and comparison with a physiological model in warm conditions. Applied Ergonomics, 42(6), 792-800. 
[71] Onofrei, E., Rocha, A. M., Catarino, A. (2012). Investigating the effect of moisture on the thermal comfort properties of functional elastic fabrics. Journal of Industrial Textiles, 42(1), 34-51.

[72] Huck, J., Maganga, O., Kim, Y. (2007). Protective overalls: evaluation garment design and fit. International Journal of Clothing Science and Technology, 9(1), 45-61.

[73] Bye, E., Labat, K. (2005). An analysis of apparel industry fit sessions. Journal of Textile and Apparel, Technology and Management, 4(3), 1-5.

[74] Harrison, D., Fan, Y., Larionov, E., Pai, D. K. (2018). Fitting close-to-body garments with $3 D$ soft body avatars VitalFit. In: 9th International Conference and Exhibition on 3D Body Scanning and Processing Technologies, 2018, pp. 184189.

[75] Sadat, A., Sayem, M., Bednall, A. (2017). A novel approach to fit analysis of virtual fashion clothing. In: 19th edition of the International Foundation of Fashion Technology Institutes Conference (IFFTI 2017), 28 March 2017 - 30 March 2017, The Amsterdam Fashion Institute (AMFI), Amsterdam, pp. 1-28.

[76] Fecht, B., Bennett, D. (1992). Robotic mannequin technology for enhanced product testing. In: McBriarty, J., Henry, N. (Eds.). Performance of protective clothing: Fourth Volume, ASTM International (West Conshohocken, PA), 1992, pp. 734-741.

[77] Adams, P. S., Keyserling, W. M. (1993). Three methods for measuring range of motion while wearing protective clothing: A comparative study. International Journal of Industrial Ergonomics, 12(3), 177-191.

[78] Fan, J., Chan, A. P. (2005). Prediction of girdle's pressure on human body from the pressure measurement on a dummy. International Journal of Clothing Science and Technology, 17(1), 6-12.

[79] Mattmann, C. (2008). Body posture detection using strain sensitive clothing.

[80] Eston, R., Reilly, T. (2009). Kinanthropometry and exercise physiology lab manual volume one : anthropometry. Taylor \& Francis (London).

[81] Sadeghi, R., Mosallanezhad, Z., Nodehi-Moghadam, A., Nourbakhsh, M. R., Biglarian, A., et al. (2015). The reliability of bubble inclinometer and tape measure in determining lumbar spine range of motion in healthy individuals and patients. Physical Treatment Journal, 5(3), 137-144.

[82] Barker, R. I., Deaton, A.S., Liston, G. (2009). Human factors performance of a prototype firefighter suit with deployable features. In: Presented at 13th international conference on environmental ergonomics, Boston, MA August 2-7.

[83] Ciesielska-wróbel, I., Denhartog, E., and Barker, R. (2017). Measuring the effects of structural turnout suits on firefighter range of motion and comfort. Ergonomics, 60(7), 997-1007.

[84] Lockhart, J. M., Bensel, C. K. (1977). The effects of layers of cold weather clothing and type of liner on the psychomotor performance of men. Technical Report NATICKJTR-77/018. US Army Natick Research and Development Command (Natick, MA).

[85] Huck, J. (1988). Protective clothing systems: a technique for evaluating restriction. Applied Ergonomics, 19(3), 185190.

[86] Li, Y. (2011). Computer aided clothing ergonomic design for thermal comfort. Sigurnost, 53(1), 29-41.
[87] Gidik, H., Ducept, S., Marolleau, A., Salaün, F., Dupont, D. (2017). Influence of textile physical properties and thermohydric behaviour on comfort. Journal of Ergonomics, 7(6), 2-9.

[88] Taylor, P., Holmér, I., Elnäs, S. (2007). Physiological evaluation of the resistance to evaporative heat transfer by clothing. no. February 2015, pp. 37-41.

[89] Taylor, P., Havenith, G., Heus, R., Lotens, W. A. (2007). Resultant clothing insulation : a function of body movement, posture, wind, clothing fit and ensemble thickness. no. December 2014, pp. 37-41.

[90] Taylor, P., Bernard, T., Ashley, C., Trentacosta, J., Kapur, $V$., et al. (2010). Critical heat stress evaluation of clothing ensembles with different levels of porosity. Ergonomics, 53(8), 1048-1058.

[91] Mohamad, G. A. (2015). The role of tests and manikin in defining fabrics thermal characteristics. International Des. Journal, 5(3), 995-1001.

[92] Fonseca, G. F. (2015). Dry heat transfer properties of clothing in wind. Textile Research Journal, 45(1), 30-34.

[93] Holmér, I. (2004). Thermal manikin history and applications. European Journal of Applied Physiology, 92(6), 614-618.

[94] Holmér, I. (2000). Thermal manikins in research and standards. National Institute for Working Life (Sweden).

[95] Fan, J., Chen, Y. S., Zhang, W. (2005). Clothing thermal insulation when sweating and when non-sweating. Elsevier Ergonomics Book Series, 3(C), 437-443.

[96] McCullough, E. A. (2005). The use of thermal manikins to evaluate clothing and environmental factors. Elsevier Ergonomics Book Series, 3(C), 403-407.

[97] Yarborough, P., Nelson, C. (2005). Performance of protective clothing: global needs and emerging markets: 8th symposium. ASTM International.

[98] Jie, Y., Wenguo, W., Ming, F. U. (2014). Coupling of a thermal sweating manikin and a thermal model for simulating human thermal response. Procedia Engineering, 84, 893-897.

[99] Fukazawa, T., Lee, AE. G., and Matsuoka, AE. T. (2004). Heat and water vapour transfer of protective clothing systems in a cold environment, measured with a newly developed sweating thermal manikin. European Journal of Applied Physiology, 92(6), 645-648.

[100] Nayak, R., Padhye, R. (2017). Manikins for textile evaluation. Elsevier Ltd (Cambridge).

[101] Oliveira, A. V. M., Gaspar, A. R., Quintela, D. A. (2011). Dynamic clothing insulation. Measurements with a thermal manikin operating under the thermal comfort regulation mode. Applied Ergonomics, 42(6), 890-899.

[102] Kaplan, S., Okur, A. (2009). Subjective evaluation methods and physiological measurements used to determine clothing thermal comfort. In: 2009 14th National Biomedical Engineering Meeting, Balcova, Izmir, Turkey, 20-22 May 2009, pp. 1-5.

[103] Li, Y. (2011). The science of clothing comfort. Textile Progress, 31(1-2), 1-35.

[104] Wang, F., Del Ferraro, S., Molinaro, V., Morrissey, M., Rossi, R. (2014). Assessment of body mapping sportswear using a manikin operated in constant temperature mode and thermoregulatory model control mode. International Journal of Biometeorology, 58(7), 1673-1682. 
[105] Kaplan, S., Okur, A. (2012). Thermal comfort performance of sports garments with objective and subjective measurements. Indian Journal of Fibre and Textile Research, 37(1), 46-54.

[106] Karlsson, I. C. M., Rosenblad, E. F. S. (1998). Evaluating functional clothing in climatic chamber tests versus field tests: A comparison of quantitative and qualitative methods in product development. Ergonomics, 41(10), 1399-1420.

[107] Kaplan, S., Okur, A. (2007). The meaning and importance of clothing comfort. Journal of Sensory Studies, 23(232), 688-706.

[108] Li, M., Li, D. P., Zhang, W. Y., Tang, X. Z. (2009). A multiple regression model for predicting comfort sensation of knitted fabric in sports condition based on objective properties. In: 2009 2nd International Conference on Information and Computing Science ICIC 2009, vol. 3, pp. 372-375

[109] Wu, H. Y., Li, J., Zhang, W. Y. (2009). Study on improving the thermal-wet comfort of clothing during exercise with an assembly of fabrics. Fibres and Textiles in Eastern Europe, 17(4), 46-51.

[110] Ho, S. S., Yu, W., Lao, T. T., Chow, D. H. K., Chung, J. $W$., et al. (2008). Comfort evaluation of maternity support garments in a wear trial. Ergonomics, 51(9), 1376-1393.

[111] Wang, Y., Cui, Y., Zhang, P., Feng, X., Shen, J., et al. (2011). A smart mannequin system for the pressure performance evaluation of compression garments. Textile Research Journal, 81(11), 1113-1123.

[112] Gill, S. (2016). Body scanning and its influence on garment development. In: Hayes. S. G., Venkatraman, $P$. (Eds.). Materials \& technology for sportswear and performance apparel. Taylor \& Francis Group (New York). pp. 325-340.

[113] Al Khaburi, J., Dehghani-sanij, A. A., Nelson, E. A., Hutchinson, J. (2014). Measurement of interface pressure applied by medical compression bandages. August 2011.

[114] Harlock, S. C., Ng, S. P., Yu, W., Fan, J. (2006). Innovation and technology of women's intimate apparel. Woodhead Publishing Limited (Cambridge, England).

[115] Anttonen, H., Niskanen, J., Meinander, H., Bartels, V., Kuklane, K., et al., (2004). Thermal manikin measurements-exact or not? International Journal of Occupational Safety and Ergonomics, 10(3), 291-300.

[116] Sardjono, C. T., et al., Review on the value of graduated elastic compression stockings after deep vein thrombosis. Thrombosis and Haemostasis, 96(6), 756766.

[117] Rothmaier, M., Clemens, F. (2008). Textile pressure sensor made of flexible plastic optical fibers. EMPA Act., no. 2008-2009, p. 55.

[118] Wang, Y., Zhang, P., Feng, X., Yao, Y. (2010). New method for investigating the dynamic pressure behavior of compression garment. International Journal of Clothing Science and Technology, 22(5), 374-383.

[119] Nakahashi, M., Morooka, H., Nakamura, N., Yamamoto, C., Morooka, H. (2005). An analysis of waist-nipper factors that affect subjective feeling and physiological response-for the design of comfortable women's foundation garments. Fiber, 61(1), 6-12.
[120] Allsop, C. A. (2012). An evaluation of base layer compression garments for sportswear. Manchester Metropolitan University.

[121] Falcão, T. A. C. (2017). Advances in human factors in wearable technologies and game design. In: International Conference on Advances in Human Factors and Wearable Technologies, 2017, p. 276.

[122] Khodasevych, I., Troynikov, O., Parmar, S. (2017). Evaluation of flexible force sensors for pressure monitoring in treatment of chronic venous disorders. Photonic Sensors, 1(17), 1-18.

[123] Tekscan. (2003). Tekscan Pressure Measurement System. South Boston.

[124] Venkatraman, P. D., Tyler, D. J. (2013). Performance of compression garments for cyclists. In: The textile institute's international conference on advances in functional textiles, 2013, pp. 1-32.

[125] Electronica, M. (2014). PicoPress Technical manual Rev.6. Italy, 2014, pp. 1-11.

[126] Sioson, E., Alexander, J. J., Mentari, A., Heitz, R., Mion, L. (1992). Effect of elastic compression stockings on venous hemodynamics in hemiplegic patients. Journal of Stroke and Cerebrovascular Diseases, 2(4), 196-201.

[127] Duffield, R., Portus, M. (2007). Comparison of three types of full-body compression garments on throwing and repeat-sprint performance in cricket players. British Journal of Sports Medicine, 41(7), 409-414.

[128] Yeung, K. W., Li, Y., Zhang, X. (2004). A 3D biomechanical human model for numerical simulation of garment-body dynamic mechanical interactions during wear. Journal of the Textile Institute Part 1 Fibre Science and Textile Technology, 95(1-6), 59-79.

[129] Nilsson, H. O., Holmer, I. (2003). Comfort climate evaluation with thermal manikin methods and computer simulation models. Indoor Air, 13(1), 28-37.

[130] Tang, K. P. M., Kan, C. W., Fan, J. T. (2014). Evaluation of water absorption and transport property of fabrics. Textile Progress, 46(1), 1-132.

[131] Rossi, M., Niedermann, R. (2012). Objective and subjective evaluation of the human thermal sensation of wet fabrics. Textile Research Journal, 82(4), 374-384.

[132] Yu, W. (2004). Objective evaluation of clothing fit. In: Fan, J., Yu, W. W.-M., Yu, W., Hunter, L. (Eds.), Clothing appearance and fit: science and technology, Woodhead Publishing Limited (Cambridge), pp. 72-88.

[133] Konstantinos, S. (2015). Assessment methods for comfort of consumer products at early stages of the development process. DTU Management Engineering.

[134] Li, Y., Dai, X.-Q. (2006). Textile biomechanical engineering. In: Li, Y., Dai, X. Q. (Eds.). Biomechanical engineering of textiles and clothing. (1st ed.). Woodhead Publishing Limited \& CRC Press LLC (Cambridge, England), pp. 1-16.

[135] Kanakaraj, P., Ramachandran, R. (2015). Active knit fabrics - functional needs of sportswear application. Journal of Textile and Apparel, Technology and Management, 9(2), 1-11.

[136] Schmidt, A., Paul, R., Classen, E., Morlock, S., Beringer, J. (2016). Comfort testing and fit analysis of military textiles. In: Wang, L. (Ed.). Performance Testing of Textiles: Methods, Technology and Applications. (1st ed.). Elsevier Ltd (Cambridge), pp. 25-37. 
[137] Lim, J., Choi, H., Roh, E. K., Yoo, H., Kim, E. (2015). Assessment of airflow and microclimate for the running wear jacket with slits using CFD simulation. Fashion and Textiles, 2(1), 1-13.

[138] Naumann, A., Roetting, M. (2007). Digital human modeling for design and evaluation of human-machine systems. MMI-Interaktiv, 12, pp. 27-35. 